\title{
5-Methyltetrahydrofolate-homocysteine methyltransferase gene polymorphism (MTR) and risk of head and neck cancer
}

\author{
A.L.S. Galbiatti ${ }^{1}$, M.T. Ruiz ${ }^{1}$, P.M. Biselli-Chicote ${ }^{1}$, L.S. Raposo ${ }^{2}$, J.V. Maniglia ${ }^{2}$, \\ E.C. Pavarino-Bertelli ${ }^{1}$ and E.M. Goloni-Bertollo ${ }^{1}$ \\ ${ }^{1}$ Unidade de Pesquisa em Genética e Biologia Molecular, \\ 2Departamento de Otorrinolaringologia e Cirurgia de Cabeça e Pescoço, \\ Faculdade de Medicina de São José do Rio Preto, São José do Rio Preto, SP, Brasil
}

\begin{abstract}
The functional effect of the A>G transition at position 2756 on the MTR gene (5-methyltetrahydrofolate-homocysteine methyltransferase), involved in folate metabolism, may be a risk factor for head and neck squamous cell carcinoma (HNSCC). The frequency of MTR A2756G (rs1805087) polymorphism was compared between HNSCC patients and individuals without history of neoplasias. The association of this polymorphism with clinical histopathological parameters was evaluated. A total of 705 individuals were included in the study. The polymerase chain reaction-restriction fragment length polymorphism technique was used to genotype the polymorphism. For statistical analysis, the chi-square test (univariate analysis) was used for comparisons between groups and multiple logistic regression (multivariate analysis) was used for interactions between the polymorphism and risk factors and clinical histopathological parameters. Using univariate analysis, the results did not show significant differences in allelic or genotypic distributions. Multivariable analysis showed that tobacco and alcohol consumption $(P<0.05), A G$ genotype $(P=0.019)$ and $G$ allele $(P=0.028)$ may be predictors of the disease and a higher frequency of the $G$ polymorphic allele was detected in men with HNSCC compared to male controls $(P=0.008)$. The analysis of polymorphism regarding clinical histopathological parameters did not show any association with the primary site, aggressiveness, lymph node involvement or extension of the tumor. In conclusion, our data provide evidence that supports an association between the polymorphism and the risk of HNSCC.
\end{abstract}

Key words: Head and neck cancer; Polymorphism; Folate metabolism; MTR gene

\section{Introduction}

Head and neck squamous cell carcinomas (HNSCC) include malignant tumors of any site in the upper aerodigestive tract, occurring in $95 \%$ of cases and being the fifth most common cancer worldwide and the most common histological type (1). Smoking and alcohol consumption, viral infections, especially the papilloma virus subtypes 16 and 18 , and vitamin and micronutrient deficiencies, including deficits of folate, vitamins $A, C$, and $E$, selenium and zinc, are risk factors for this disease (1-6).

Folate metabolism plays an important role in carcinogenesis because of its involvement in both DNA methylation and nucleotide synthesis. DNA methylation is the transfer of methyl groups $(\mathrm{CH} 3)$ to the $\mathrm{C} 5$ position of cytosine residues located in cytosine-guanine dinucleotides, by reac- tions catalyzed by proteins called DNA methyltransferases (7). This epigenetic modification of the DNA has several functional roles including control of gene expression (8), maintenance of genomic stability (9) and stability of the chromatin structure (10).

The relationship between polymorphisms of genes involved in folate metabolism and the risk for cancer is related to their effect on DNA methylation and synthesis and, thus, on the maintenance of chromatin structure and chromosome stability (6).

The 5-methyltetrahydrofolate-homocysteine methyltransferase (MTR) gene, located in chromosome 1q43 (10), encodes the methionine synthase enzyme, which has a role in folate metabolism, catalyzing the remethylation of

Correspondence: E.M. Goloni-Bertollo, Departamento de Biologia Molecular, FAMERP, Av. Brigadeiro Faria Lima, 5416, 15090-000 São José do Rio Preto, SP, Brasil. E-mail: eny.goloni@famerp.br

Received September 2, 2009. Accepted April 12, 2010. Available online April 22, 2010. Published May 14, 2010. 
homocysteine (Hcy) to methionine, a reaction essential to adequately maintain normal methionine and intracellular Hcy concentrations (11). An adenine to guanine transition at position 2756 (rs185087) of the MTR gene results in the substitution of the amino acid, aspartic acid, with glycine in codon 919 of the protein and is related to alterations in the folate metabolic pathway, thus possibly influencing the risk of cancer $(12,13)$.

Research results on the influence of this polymorphism on the development of cancer are contradictory. Some studies have shown associations with colon (14), lung (15) and breast cancer (16), and relationships with tumor aggressiveness and variable responses to esophageal cancer treatment (17). Other studies did not confirm associations between the polymorphism and different types of cancer, including colorectal (18), lung (19), bladder (20), and stomach cancer (21).

Three studies investigated the MTRA2756G polymorphism with respect to head and neck cancer. Zhang et al. (22), when analyzing the MTR A2756G polymorphism in 721 cancer patients and 1234 control individuals, observed differences in the genotype frequencies between the two groups. They also showed that the 2756AG genotype was associated with a significantly increased risk of HNSCC among younger subjects, women and former drinkers, in particular tumors of the oral cavity. In another study, Suzuki et al. (23) analyzed 237 HNSCC patients and 711 controls in Japan but did not identify differences between the two groups. Kruszyna et al. (24) analyzed 131 men diagnosed with squamous cell carcinoma of the larynx and 250 randomly selected, unrelated healthy male blood donors and other healthy volunteers in the Polish population and suggested that the MTR $2756 \mathrm{G}$ allele may contribute to the risk of laryngeal cancer.

Based on the above evidence, the aim of this study was to compare the frequencies of the MTR A2756G polymorphism between head and neck cancer patients and individuals with no history of cancer, and to determine if there were an association of this polymorphism with clinical histopathological parameters.

\section{Patients and Methods}

A total of 705 individuals (236 patients and 469 controls) with a mean age of $52.5 \pm 13.7$ years were included in the study.

The study protocol was approved by the National Ethics Committee (SISNEP 0976.0.140.000-05). The case group consisted of 236 patients who were diagnosed with head and neck cancer at Hospital de Base, São José do Rio Preto, SP, Brazil. Informed consent was obtained from all individuals enrolled in the study. The diagnosis was made from pathological specimens after total excision or a biopsy. The inclusion criterion was squamous cell carcinoma tumor cell types and the exclusion criterion was patients previously treated for tumors. The primary anatomic sites were oral cavity $(\mathrm{N}=92,40 \%)$, pharynx $(\mathrm{N}=59,25 \%)$, and larynx $(\mathrm{N}=76,32.2 \%)$ and $9(2.8 \%)$ patients with unknown primary site of the tumor.

All required information about clinical histopathological parameters was obtained from the patients' medical records. The average survival was $31.7 \pm 27.1$ months. The treatment options for the patients were surgery, radiotherapy and chemotherapy.

The tumors were classified according to the parameters of the International Union of Cancer Control (UICC), 2002, and the American Joint Committee for Cancer (AJCC), 2002, based on three criteria: extension of the tumor (T), presence of regional lymph node involvement $(\mathrm{N})$, and presence of metastasis at a distance (M) (25). The clinical stage (TNM) was used to analyze aggressiveness, with tumors being grouped as non-aggressive (stages I and II) and aggressive (stages III and IV).

The control group consisted of 469 Brazilian blood donors without a diagnosis of cancer according to government guidelines for donated blood that is tested for 20 related diseases (http://www.hemonline.com.br/portarias/rdc153/ indexframe.htm). The inclusion criterion was age of more than 40 years and the exclusion criterion was a family history of cancer. Each eligible subject was interviewed to obtain data on age, gender, smoking habit, use of alcohol, and family history of cancer. Patients and controls were followed up for 60 months.

The variables analyzed were gender, exposure to risk factors (tobacco and alcohol consumption), primary site of occurrence, aggressiveness, extension of the tumor, and lymph node involvement. Individuals who had smoked more than 100 cigarettes in their lifetime and at the time of the interview continued to smoke either every day or at least on some days were considered to be smokers. Individuals who drank 4 doses of alcohol per week were considered to be alcohol consumers $(26,27)$.

Genomic DNA was obtained from peripheral blood according to technique of Miller et al. (28). The polymerase chain reaction-restriction fragment length polymorphism (PCR-RFLP) technique was used to determine genotypes of the MTR A2756G polymorphism (rs1805087). The primers used were: sense 5'-CCA GGG TGC GAC GTA TAC AG-3' and anti-sense 5'-GCC TTT TAC ACT CCT CAA AAC C-3'. Amplification was obtained with initial denaturation at $94^{\circ} \mathrm{C}$ for $4 \mathrm{~min}$, followed by 30 cycles of $1 \mathrm{~min}$ of DNA denaturation at $94^{\circ} \mathrm{C}, 1-\mathrm{min}$ primer annealing at $56^{\circ} \mathrm{C}$, and 1 -min extension at $72^{\circ} \mathrm{C}$. A final extension of $10 \mathrm{~min}$ at $72^{\circ} \mathrm{C}$ was carried out. The product of $498 \mathrm{bp}$ was submitted to digestion with the Haelll restriction enzyme for $2 \mathrm{~h}$ at $37^{\circ} \mathrm{C}$ according to manufacturer guidelines. Fragments of 390,123 , and 85 bp were generated when the $G$ polymorphic allele was present and 413- and 85-bp fragments were observed with the A allele. 


\section{Statistical analysis}

Groups were compared by the chi-square test (univariate analysis). Utilizing the BioEstat computer program, this test was also used to analyze Hardy-Weinberg equilibrium. Multiple logistic regression models were used to determine the interaction effect between the genetic polymorphisms and variables related to HNSCC. One model included gender (reference: female), smoking (reference: non-smokers) and drinking habits (reference: non-drinkers) using the Minitab for Windows computer program (Version 12.22). $\mathrm{P}<0.05$ was considered to be statistically significant. Results are shown as odds ratio (OR) and 95\% confidence intervals $(95 \% \mathrm{Cl})$.

The clinical histopathological parameters were analyzed by multiple logistic regression. Tumors were classified as low $\mathrm{T}(\mathrm{T} 1, \mathrm{~T} 2)$ and high $\mathrm{T}(\mathrm{T} 3, \mathrm{~T} 4)$. The $\mathrm{N}$ classification was dichotomized into no lymph node involvement (N0) and involvement (N1, N2, N3). Tumors were divided into early stage (stages I and II) and advanced stage (stages III and IV) categories.

The Kaplan-Meier method was used to evaluate survival rates and time of disease recurrence. The log-rank test was used to assess differences related to the different genotypes.

\section{Results}

There were statistically significant differences between patients and controls regarding gender, alcohol consumption and smoking $(P<0.05)$. Five hundred and twenty-nine $(75 \%)$ participants were men (203 patients and 326 controls) and $176(25 \%)$ were women (33 patients and 143 controls). Of the cases, $77.97 \%$ consumed alcohol compared to $46.70 \%$ of the controls. Smoking also differed greatly between cases $(89.41 \%)$ and controls (48.83\%).

Hardy-Weinberg equilibrium showed that the genotypic distributions were in equilibrium for both groups (case: $\mathrm{X}^{2}=$ 0.028; $P=0.868$, and control: $X^{2}=2.868 ; P=0.09$ ).

For the MTR 2756 polymorphisms, AA, AG, and GG genotype frequencies were $65.7,31.0$, and $3.3 \%$, respectively, for the cases, and $72.5,24.0$, and $3.5 \%$, respectively, for the controls. The variant MTR 2756A allele frequencies were 0.81 among the cases and 0.85 among the controls, while the MTR $2756 \mathrm{G}$ allele frequencies were 0.19 and 0.15 among cases and controls, respectively.

The frequency of the $G$ polymorphic allele (individuals carrying at least one $G$ allele - genotypes: $A G$ and $G G$ ) was stratified by gender. There was a higher frequency of carriers of the $G$ variant allele in men with head and neck cancer compared to the group of men with no history of cancer $(P=0.008)$. No difference between patients and controls $(P=0.335)$ was observed for the women.

As matching demographic data and risk factors between patients with cancer and control individuals was not possible, multivariable analysis was performed to adjust these
Table 1. Distribution of demographic data, risk factors, genotypes, MTR 2756 alleles, and odds ratio (OR) for head and neck cancer.

\begin{tabular}{|c|c|c|}
\hline Variables & $\mathrm{N}(\%)$ & OR $(95 \% \mathrm{Cl})$ \\
\hline \multicolumn{3}{|l|}{ Tobacco consumption } \\
\hline Non-smokers & $301(37.3)$ & Reference \\
\hline Smokers & $504(62.7)$ & $4.49(2.68-7.54)^{\star}$ \\
\hline \multicolumn{3}{|l|}{ Alcohol consumption } \\
\hline Alcohol non-consumers & $338(42)$ & Reference \\
\hline Alcohol consumers & $467(58)$ & $2.30(1.46-3.63)^{\star}$ \\
\hline \multicolumn{3}{|l|}{ Gender } \\
\hline Female & $263(32.6)$ & Reference \\
\hline Male & $595(67.4)$ & $1.18(0.69-2.01)$ \\
\hline \multicolumn{3}{|l|}{ Age } \\
\hline$<42$ years & $217(27)$ & Reference \\
\hline $42-51$ years & $185(23)$ & $4.72(2.29-9.72)^{*}$ \\
\hline $52-63$ years & $191(23.7)$ & $19.45(9.55-39.59)^{*}$ \\
\hline$>63$ years & $212(26.3)$ & $11.01(5.33-22.72)^{\star}$ \\
\hline \multicolumn{3}{|l|}{ MTR 2756 genotypes } \\
\hline AA & $523(65)$ & Reference \\
\hline$A G$ & $247(30.6)$ & $1.69(1.09-2.62)^{*}$ \\
\hline GG & $35(4.4)$ & $1.08(0.37-3.13)$ \\
\hline \multicolumn{3}{|l|}{ MTR 2756 alleles } \\
\hline$A$ & $682(76.4)$ & Reference \\
\hline$G$ & $210(23.6)$ & $1.60(1.05-2.44)^{*}$ \\
\hline
\end{tabular}

$M T R=5$-methyltetrahydrofolate-homocysteine methyltransferase. ${ }^{*} \mathrm{P}<0.05$ (muliple logistic regression).

variables. The following variables were included: gender, tobacco and alcohol consumption, and MTR A2756G polymorphism. Smoking $(P<0.05)$, alcohol consumption $(P<0.05), A G$ heterozygous genotype $(P=0.019)$, and the $G$ polymorphic allele $(P=0.028)$ were predictors of the disease (Table 1).

Analysis of polymorphisms and clinical parameters did not detect any association with the primary tumor site $(P=$ $0.12)$, tumor extension $(P=0.38)$, lymph node involvement $(P=0.35)$, or tumor stage $(P=0.18)$.

The Kaplan-Meier survival curves by genotype are presented in Figure 1A, and did not demonstrate any association between polymorphisms and overall survival $(\mathrm{P}=$ $0.52)$. Moreover, no association was observed for the time of recurrence of the disease $(P=0.25$; Figure $1 \mathrm{~B})$.

\section{Discussion}

A review of published data showed that the most important factors predisposing factors to the development of HNSCC, present in $90 \%$ of cases, are alcohol and tobacco consumption (1) and our study confirms this association. Additionally, a significant association was confirmed between 

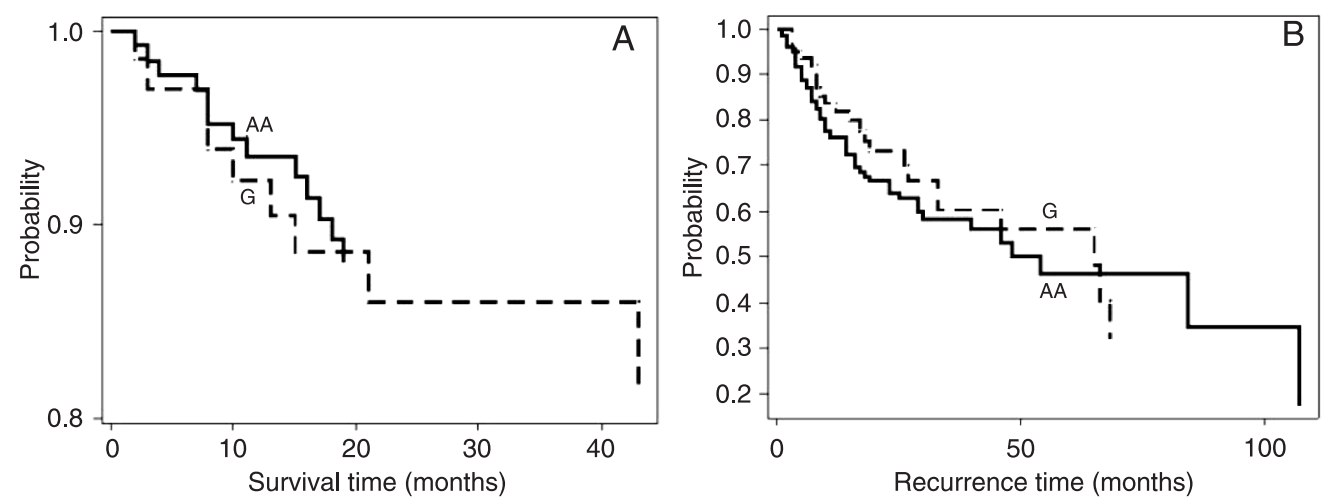

Figure 1. Kaplan-Meier curves for overall survival $(P=0.52)(A)$ and recurrence time $(P=0.25)(B)$ for patients according to MTR A2756G polymorphism. There was no statistical difference between the curves for subjects with the AA genotype and subjects with at least one mutant allele ( $G$ allele). MTR $=5$-methyltetrahydrofolate-homocysteine methyltransferase.

gender and this disease, as previously reported by Argiris et al. (29), who showed that males are the most affected by this disease.

Using univariate analysis, the results of the current study did not demonstrate significant differences between groups with respect to allele and genotype distributions, similar to the data reported by Suzuki et al. (23). The results also show that men with head and neck cancer had a higher frequency of the $G$ polymorphic allele than men with no history of cancer, thus supporting the results of Kruszyna et al. (24), who showed that the frequency of the $G$ allele was 1.55 times higher in male patients with laryngeal cancer compared to male controls. Our findings did not confirm those of Zhang and et al. (22), who reported that the MTR 2756AG genotype is associated with an increased risk for this type of cancer, especially in younger individuals, women and former smokers.

Multivariable analysis performed after adjusting for age, gender and tobacco and alcohol consumption showed that the $G$ polymorphic allele and the AG heterozygous genotype are associated with increased risk for the disease with OR of 1.60 and 1.69, respectively. Associations between MTR A2756G polymorphism and the development of some types of cancer have been shown in previous studies $(30,31)$.

Only three studies have investigated this polymorphism regarding head and neck cancer (22-24). Zhang et al. (22) and Kruszyna et al. (24) reported differences in the MTR A2756G genotype frequencies between head and neck cancer patients and controls and between larynx cancer patients and controls, respectively, while Suzuki et al. (23) did not observe any association between the presence of the polymorphism and the risk for the disease. The latter investigators demonstrated an interaction of alcohol consumption with the 2756 GG genotype in the risk for head and neck cancer.

Folate is an essential nutrient, which has important roles in the synthesis (genetics), repair, and methylation (epigenetics) of DNA. It is used to transport a methyl group, which is essential for the de novo synthesis of deoxynucleoside triphosphate and methionine.

The functional variant, MTRA2756G, encoding the MTR enzyme (OMIM 156570) uses methyl-tetrahydrofolate as a methyl donor for the remethylation of $\mathrm{Hcy}$ to form methionine. Methionine adenosyltransferase, using methionine and ATP, induces the formation of S-adenosylmethionine (32).

Folate deficiency associated with the MTR GG or MTR $A G$ genotypes may increase cancerogenesis by reducing the formation of S-adenosylmethionine, leading to DNA hypomethylation and cancer and may also induce uracil misincorporation into DNA in place of thymine during DNA replication, which, along with DNA hypomethylation, results in impaired DNA repair, DNA strand breakage, and chromosome damage (33). The study of Paz and collaborators (34) showed that hypomethylation of genomic DNA may be associated with the MTR A2756G polymorphism.

Studies on other types of cancer also found a link between the MTR GG genotype and extensive genomic hypomethylation as well as decreased promoter hypermethylation of tumor suppressor genes $(35,36)$.

In the present study, Hcy concentration was not measured but several studies have shown that the MTRA2756G polymorphism has also been associated with variations in Hcy concentrations. However, the quantitative impact of this polymorphism on cellular Hcy concentrations has not been determined. Studies have shown an association between the MTR GG genotype and lower plasma Hcy levels compared to the MTR AA genotype, showing that the MTR A2756G polymorphism contributes to enhanced methionine synthesis and an increase in intracellular S-adenosylmethionine concentration (13,37). However, Laraqui et al. (38) observed a correlation between the polymorphic allele $(G)$ and moderately high Hcy levels. 
Our study did not detect any associations of the MTR A2756G polymorphism with the site of occurrence, aggressiveness, tumor extension, or lymph node involvement. Zhang et al. (22) showed an increased frequency of the polymorphism related to tumors of the oral cavity, while Kruzsyna et al. (24) did not find any association of this polymorphism with laryngeal cancer. After an exhaustive literature review, no previous studies were found regarding the possible association between this polymorphism and clinical histopathological parameters or with the risk of cancer development.

Marchal et al. (39) reported that the presence of the MTR $2756 \mathrm{G}$ allele is a factor of tumor aggressiveness in prostate cancer. No data were found in the literature assessing survival according to MTRA2756G polymorphism in patients with head and neck cancer.

In conclusion, although there is an association be-

\section{References}

1. Marcu LG, Yeoh E. A review of risk factors and genetic alterations in head and neck carcinogenesis and implications for current and future approaches to treatment. J Cancer Res Clin Oncol 2009; 135: 1303-1314.

2. Choi SW, Mason JB. Folate and carcinogenesis: an integrated scheme. J Nutr 2000; 130: 129-132.

3. Raval GN, Sainger RN, Rawal RM, Patel JB, Patel BP, Jha $\mathrm{FP}$, et al. Vitamin $\mathrm{B}(12)$ and folate status in head and neck cancer. Asian Pac J Cancer Prev 2002; 3: 155-162.

4. Lingen M, Sturgis EM, Kies MS. Squamous cell carcinoma of the head and neck in nonsmokers: clinical and biologic characteristics and implications for management. Curr Opin Oncol 2001; 13: 176-182.

5. Pelucchi C, Talamini R, Negri E, Levi F, Conti E, Franceschi $S$, et al. Folate intake and risk of oral and pharyngeal cancer. Ann Oncol 2003; 14: 1677-1681.

6. Kane MA. The role of folates in squamous cell carcinoma of the head and neck. Cancer Detect Prev 2005; 29: 46-53.

7. D'Alessio AC, Szyf M. Epigenetic tete-a-tete: the bilateral relationship between chromatin modifications and DNA methylation. Biochem Cell Biol 2006; 84: 463-476.

8. Ehrlich M. The ICF syndrome, a DNA methyltransferase 3B deficiency and immunodeficiency disease. Clin Immunol 2003; 109: 17-28.

9. Tuck-Muller CM, Narayan A, Tsien F, Smeets DF, Sawyer J, Fiala ES, et al. DNA hypomethylation and unusual chromosome instability in cell lines from ICF syndrome patients. Cytogenet Cell Genet 2000; 89: 121-128.

10. Leclerc D, Campeau E, Goyette P, Adjalla CE, Christensen $B$, Ross $M$, et al. Human methionine synthase: cDNA cloning and identification of mutations in patients of the cblG complementation group of folate/cobalamin disorders. Hum Mol Genet 1996; 5: 1867-1874.

11. Sharp L, Little J. Polymorphisms in genes involved in folate metabolism and colorectal neoplasia: a HuGE review. Am J Epidemiol 2004; 159: 423-443.

12. van der Put NM, van der Molen EF, Kluijtmans LA, Heil SG, Trijbels JM, Eskes TK, et al. Sequence analysis of the tween MTR A2756G polymorphism and the risk for head and neck cancer and a higher frequency of carriers of the $G$ allele variant in men with head and neck cancer compared to men without any history of cancer, studies of other enzymes involved in folate metabolism, their plasma concentrations and other derivatives could contribute to a better understanding of the factors involved in the etiology of head and neck cancer.

\section{Acknowledgments}

The authors wish to thank all those participating in this study, Prof. Adília M. Pires Sciarra for her help in writing the text, Prof. Dr. José A. Cordeiro and Prof. Dr. Moacir F. Godoy for their help in statistical analysis and FAMERP/FUNFARME. Research supported by FAPESP (\#04/14573-3), CAPES and CNPq (\#477665/2004-7, \#305462/2005-9). coding region of human methionine synthase: relevance to hyperhomocysteinaemia in neural-tube defects and vascular disease. QJM 1997; 90: 511-517.

13. Harmon DL, Shields DC, Woodside JV, McMaster D, Yarnell JW, Young IS, et al. Methionine synthase D919G polymorphism is a significant but modest determinant of circulating homocysteine concentrations. Genet Epidemiol 1999; 17: 298-309.

14. Chen K, Song L, Jin MJ, Fan CH, Jiang QT, Yu WP. [Association between genetic polymorphisms in folate metabolic enzyme genes and colorectal cancer: a nested case-control study]. Zhonghua Zhong Liu Za Zhi 2006; 28: 429-432.

15. Shi Q, Zhang Z, Li G, Pillow PC, Hernandez LM, Spitz MR, et al. Polymorphisms of methionine synthase and methionine synthase reductase and risk of lung cancer: a case-control analysis. Pharmacogenet Genomics 2005; 15: 547-555.

16. Lissowska J, Gaudet MM, Brinton LA, Chanock SJ, Peplonska B, Welch R, et al. Genetic polymorphisms in the one-carbon metabolism pathway and breast cancer risk: a population-based case-control study and meta-analyses. Int J Cancer 2007; 120: 2696-2703.

17. Sarbia M, Stahl M, Von Weyhern C, Weirich G, PuhringerOppermann F. The prognostic significance of genetic polymorphisms (Methylenetetrahydrofolate Reductase C677T, Methionine Synthase A2756G, Thymidilate Synthase tandem repeat polymorphism) in multimodally treated oesophageal squamous cell carcinoma. Br J Cancer 2006; 94: 203-207.

18. Chen K, Jiang QT, He HQ. Relationship between metabolic enzyme polymorphism and colorectal cancer. World J Gastroenterol 2005; 11: 331-335.

19. Suzuki T, Matsuo K, Hiraki A, Saito T, Sato S, Yatabe $Y$, et al. Impact of one-carbon metabolism-related gene polymorphisms on risk of lung cancer in Japan: a case control study. Carcinogenesis 2007; 28: 1718-1725.

20. Moore LE, Malats N, Rothman N, Real FX, Kogevinas M, Karami S, et al. Polymorphisms in one-carbon metabolism and trans-sulfuration pathway genes and susceptibility to 
bladder cancer. Int J Cancer 2007; 120: 2452-2458.

21. Zhang FF, Terry MB, Hou L, Chen J, Lissowska J, Yeager M, et al. Genetic polymorphisms in folate metabolism and the risk of stomach cancer. Cancer Epidemiol Biomarkers Prev 2007; 16: 115-121.

22. Zhang Z, Shi Q, Liu Z, Sturgis EM, Spitz MR, Wei Q. Polymorphisms of methionine synthase and methionine synthase reductase and risk of squamous cell carcinoma of the head and neck: a case-control analysis. Cancer Epidemiol Biomarkers Prev 2005; 14: 1188-1193.

23. Suzuki T, Matsuo K, Hasegawa Y, Hiraki A, Wakai K, Hirose $\mathrm{K}$, et al. One-carbon metabolism-related gene polymorphisms and risk of head and neck squamous cell carcinoma: case-control study. Cancer Sci 2007; 98: 1439-1446.

24. Kruszyna L, Lianeri M, Rydzanicz M, Gajecka M, Szyfter K, Jagodzinski PP. Polymorphic variants of folate metabolism genes and the risk of laryngeal cancer. Mol Biol Rep 2010; 37: 241-247.

25. Sobin $\mathrm{LH}$, Wittelind $\mathrm{CH}$. International union against cancer: TNM classification of malignant tumours. 6th edn. New York: Wiley; 2000.

26. Ahrendt SA, Chow JT, Yang SC, Wu L, Zhang MJ, Jen J, et al. Alcohol consumption and cigarette smoking increase the frequency of p53 mutations in non-small cell lung cancer. Cancer Res 2000; 60: 3155-3159.

27. Kjaerheim K, Gaard M, Andersen A. The role of alcohol, tobacco, and dietary factors in upper aerogastric tract cancers: a prospective study of 10,900 Norwegian men. Cancer Causes Control 1998; 9: 99-108.

28. Miller SA, Dykes DD, Polesky HF. A simple salting out procedure for extracting DNA from human nucleated cells. Nucleic Acids Res 1988; 16: 1215.

29. Argiris A, Karamouzis MV, Raben D, Ferris RL. Head and neck cancer. Lancet 2008; 371: 1695-1709.

30. Lima CS, Ortega MM, Ozelo MC, Araujo RC, De Souza CA, Lorand-Metze I, et al. Polymorphisms of methylenetetrahydrofolate reductase (MTHFR), methionine synthase (MTR), methionine synthase reductase (MTRR), and thymidylate synthase (TYMS) in multiple myeloma risk. Leuk Res 2008;
32: 401-405.

31. Goode EL, Potter JD, Bamlet WR, Rider DN, Bigler J. Inherited variation in carcinogen-metabolizing enzymes and risk of colorectal polyps. Carcinogenesis 2007; 28: 328-341.

32. Chen LH, Liu ML, Hwang HY, Chen LS, Korenberg J, Shane B. Human methionine synthase. cDNA cloning, gene localization, and expression. J Biol Chem 1997; 272: 36283634.

33. Ames BN. DNA damage from micronutrient deficiencies is likely to be a major cause of cancer. Mutat Res 2001; 475: 7-20.

34. Paz MF, Avila S, Fraga MF, Pollan M, Capella G, Peinado $M A$, et al. Germ-line variants in methyl-group metabolism genes and susceptibility to DNA methylation in normal tissues and human primary tumors. Cancer Res 2002; 62: 4519-4524.

35. Das PM, Singal R. DNA methylation and cancer. J Clin Oncol 2004; 22: 4632-4642.

36. Gemmati D, Ongaro A, Scapoli GL, Della Porta M, Tognazzo $\mathrm{S}$, Serino ML, et al. Common gene polymorphisms in the metabolic folate and methylation pathway and the risk of acute lymphoblastic leukemia and non-Hodgkin's lymphoma in adults. Cancer Epidemiol Biomarkers Prev 2004; 13: 787794.

37. Tsai MY, Bignell M, Yang F, Welge BG, Graham KJ, Hanson $N Q$. Polygenic influence on plasma homocysteine: association of two prevalent mutations, the 844ins68 of cystathionine beta-synthase and $A(2756) G$ of methionine synthase, with lowered plasma homocysteine levels. Atherosclerosis 2000; 149: 131-137.

38. Laraqui A, Allami A, Carrie A, Coiffard AS, Benkouka F, Benjouad A, et al. Influence of methionine synthase (A2756G) and methionine synthase reductase (A66G) polymorphisms on plasma homocysteine levels and relation to risk of coronary artery disease. Acta Cardiol 2006; 61: 51-61.

39. Marchal C, Redondo M, Reyes-Engel A, Perea-Milla E, Gaitan MJ, Machuca J, et al. Association between polymorphisms of folate-metabolizing enzymes and risk of prostate cancer. Eur J Surg Oncol 2008; 34: 805-810. 